\title{
Short communication: Effect of straw inclusion rate in a dry total mixed ration on the behavior of weaned dairy calves
}

\author{
M. J. Groen, ${ }^{*} \dagger$ M. A. Steele, $\ddagger^{1}$ and T. J. DeVries ${ }^{* 2}$ \\ *Department of Animal and Poultry Science, University of Guelph, Kemptville Campus, 830 Prescott Street, Kemptville, ON, K0G 1J0 Canada \\ †Animal Nutrition Group, Wageningen University, PO Box 338, 6700 AH Wageningen, the Netherlands \\ $\ddagger$ Nutreco Canada, 150 Research Lane, Guelph, ON, N1G 4T2 Canada
}

\section{ABSTRACT}

The primary objective of this study was to determine the effect of straw inclusion levels on the feeding behavior of young, weaned calves adapted to a dry total mixed ration (TMR) composed of a multitextured concentrate and chopped straw. A secondary objective was to determine how developed feeding patterns persist after calves were switched to a conventional silage-based diet. Ten Holstein bull calves $(91 \pm 2.4 \mathrm{~d}$ of age, weighing $136 \pm 12.3 \mathrm{~kg}$ ) were assigned to 1 of 2 treatments: a TMR containing [dry matter (DM) basis] either (1) $85 \%$ concentrate and $15 \%$ chopped straw for $10 \mathrm{wk}$ (wk 1 to 10 ) or (2) $85 \%$ concentrate and $15 \%$ chopped straw for 5 wk (wk 1 to 5 ), then $70 \%$ concentrate and $30 \%$ chopped straw for $5 \mathrm{wk}$ (wk 6 to 10). After $10 \mathrm{wk}$, all animals were transitioned to a TMR containing (DM basis) $42.3 \%$ corn silage and $57.7 \%$ haylage for $2 \mathrm{wk}$ (wk 11 to 12). During wk 1 to 5, all calves had similar DMI $(5.5 \mathrm{~kg} / \mathrm{d})$, average daily gain $(1.7 \mathrm{~kg} / \mathrm{d})$, feed efficiency (3.5 kg of DM $/ \mathrm{kg}$ of gain), and eating time $(151.9 \mathrm{~min} / \mathrm{d})$. During wk 6 to 10 , calves transitioned to the $70 \%$ diet ate less DM (5.5 vs. $7.4 \mathrm{~kg} / \mathrm{d})$, grew more slowly (1.3 vs. $1.6 \mathrm{~kg} / \mathrm{d}$ ), sorted more against long forage particles (62.8 vs. $103.8 \%$ ), and had greater feeding times (194.9 vs. $102.6 \mathrm{~min} / \mathrm{d}$ ). The difference in feeding time occurred only during the first $8 \mathrm{~h}$ after feed delivery. Despite similar DMI $(5.2 \mathrm{~kg} / \mathrm{d})$ and average daily gain $(1.1 \mathrm{~kg} / \mathrm{d})$ in wk 11 to 12 , differences in behavior were observed resulting from previous diets. In wk 11 to 12 , calves previously fed the $70 \%$ diet continued to have a longer meal immediately after feed delivery. Overall, the results indicate that diluting a dry TMR containing a multitextured concentrate and chopped straw with more straw resulted in calves spending more time feeding and having longer meals immediately after feed

Received October 14, 2014.

Accepted December 6, 2014.

${ }^{1}$ Current address: Department of Agricultural, Food and Nutritional Science, University of Alberta, Edmonton, AB, T6G 2P5 Canada.

${ }^{2}$ Corresponding author: tdevries@uoguelph.ca delivery; this feeding pattern carried over after calves were transitioned to a silage-based ration.

Key words: feeding behavior, straw, dairy calf, total mixed ration

\section{Short Communication}

Total mixed rations are designed as a homogeneous mixture with the goal to minimize the selective consumption of individual feed components by dairy cattle (Coppock et al., 1981). It is for this reason that providing feed as a TMR, rather than separately feeding the grain concentrate and forage components, is the most common method of feed delivery used on commercial dairy farms for nearly all classes of animals over 6 mo of age. Recent data suggests that providing TMR to young, weaned heifers results in heifers consuming their ration more consistently and reduces the amount of sorting against forage and for concentrate (DeVries and von Keyserlingk, 2009; Greter et al., 2010a). Feeding a TMR to heifers from a young age not only has immediate behavioral effects, but may also have longer-term benefits to these animals. Greter et al. (2010b) found that heifers previously fed a top-dressed ration, maintained similar feeding patterns (whereby they were slug feeding their concentrate) after they were switched to a silage-based TMR (for a period of $7 \mathrm{wk}$ ).

Currently little is known about the effects of feeding a dry TMR to young, weaned dairy calves. The primary objective of our study was to determine the effect of straw inclusion level on the feeding behavior of weaned calves adapted to a dry TMR composed of a multitextured concentrate and chopped straw. A secondary objective was to determine how feeding patterns developed during this period persist after calves are switched to conventional silage-based diet.

Ten male Holstein calves were used in our study. The calves were purchased at birth from commercial dairy farms in eastern Ontario and were housed at the University of Guelph, Kemptville Campus Dairy Education and Research Centre (Kemptville, ON, Canada). The calves were managed according to standard operating 
procedures of this facility, in accordance with policies and guidelines of the Canadian Council on Animal Care (CCAC, 2009).

Prior to the present study, calves were pen-housed either in pairs or individually during the milk feeding period (d 1 to 49 of life) and offered milk replacer [Shur-Gain Optivia (26:16) Advantage Milk Replacer; Nutreco Canada Inc., Guelph, ON, Canada] ad libitum via a teat, a texturized concentrate, and water. Throughout the postweaning period (d 50 to 91), calves were provided a complete high-fiber pelleted diet (ShurGain High Fiber Dairy Heifer Ration; Nutreco Canada Inc.; $91 \%$ DM, $21 \%$ CP, $18 \%$ ADF, 36\% NDF).

For our study, at $91 \pm 2.4 \mathrm{~d}$ of age (mean $\pm \mathrm{SD}$ ), calves $(136.0 \pm 12.3 \mathrm{~kg})$ were individually housed in pens $(2.44 \times 1.83 \mathrm{~m}$; width $\times$ depth $)$. The front of each pen had 2 gates. The left gate had 2 openings for access to water pails (diameter $=33.7 \mathrm{~cm}$, height $=31.1 \mathrm{~cm}$, capacity $=19 \mathrm{~L}$ ) mounted on the outside. The right gate had 2 openings for access to a feed bucket (width $=81.3 \mathrm{~cm}$, height $=42.2 \mathrm{~cm}$, capacity $=106 \mathrm{~L}$ ) mounted on the outside. Pens were located under a 3-sided, roofed barn and were bedded with wood shavings, with bedding replaced $3 \times$ a week and fresh bedding added as needed. The study was conducted between August and November 2013.

To ensure that the number of animals per treatment was adequate to detect statistical differences in treatment response, a power analysis (Morris, 1999; Hintze, 2008) was performed before the study for the primary response variables, including feed sorting and feeding behavior. Estimates of variation for these variables (mean $\mathrm{CV}=12 \%$ ) were based on previously reported values (DeVries and von Keyserlingk, 2009; Greter et al., 2010a; Miller-Cushon and DeVries, 2011a; MillerCushon et al., 2013b). From the power analysis, it was determined that at $80 \%$ power, treatment differences of $\sim 15 \%$ could be detected at this sample size.

Calves were randomly assigned to 1 of 2 treatments: a TMR containing (on a DM basis) either (1) 85\% concentrate (Shur-Gain Optivia 22\% Rumimax Transition Calf Ration; Nutreco Canada Inc.) and 15\% chopped wheat straw for $10 \mathrm{wk}$ (wk 1 to 10) or (2) $85 \%$ concentrate and $15 \%$ chopped wheat straw for 5 wk (wk 1 to 5 ), then $70 \%$ concentrate and $30 \%$ chopped wheat straw for 5 wk (wk 6 to 10). All animals were on the same diet ( $85 \%$ concentrate) for the first 5 wk to allow calves to adapt to the diet, in particular to the forage component for which they previously had no experience. During those first $10 \mathrm{wk}$, TMR was manually weighed and mixed for each animal daily. Wheat straw was chopped with a New Holland 355 Grinder Mixer (New Holland Inc., New Holland, PA) to pass through a $1.9-\mathrm{cm}$ mesh screen. At $23 \mathrm{wk}$ of age, all animals were transitioned to a silage-based TMR, containing $42.3 \%$ corn silage and $57.7 \%$ haylage, on a DM basis, for a period of $2 \mathrm{wk}$ (wk 11 to 12). The TMR was prepared daily in a TMR mixer wagon (Jaylor 4425, Jaylor Fabricating, Orton, ON, Canada) and manually weighed for each animal. The ingredient and chemical composition of the diets are listed in Table 1. Feed was provided once daily at $1000 \mathrm{~h}$ in amounts to ensure $10 \%$ orts; this level of orts was chosen to ensure sufficient feed was leftover to sample for feed sorting. Water and trace mineral salt blocks (Windsor TM Stock Salt, The Canadian Salt Company Limited, Pointe-Claire, QC, Canada) were provided ad libitum.

Intake of feed was recorded daily based on offered and refused quantities of feed. The calves were weighed at the same time each day on 2 consecutive days each week. Weekly ADG was calculated as the difference between average weights taken 1 wk apart divided by 7. Feed-to-gain ratio was calculated by dividing DMI by ADG for each calf.

The behavior of calves was recorded throughout the study using 6 color video cameras (Day/Night Camera, model no. WV-CP504; Panasonic, Osaka, Japan) fitted with an F0.95, 2.8- to 8-mm lens (Fujinon CCTV lens, Fuji, Tokyo, Japan). Cameras were connected to a digital video recorder (Digital Disk Recorder, model no. WJ-HD616K, Panasonic) set to record at 7.5 images/s. Cameras were positioned above the pens such that each individual pen was fully visible from 1 of the cameras ( $\sim 2 \mathrm{~m}$ in front of the pens and $4 \mathrm{~m}$ from the pen floor). Four red lights $(100 \mathrm{~W})$ were spaced evenly between cameras and placed on a timer to provide enough light to record during nighttime hours. Characterization of feeding behavior, using digital video recordings, occurred on $3 \mathrm{~d}$ (d 1 to 3 ) in wk 1, 3, 5, 6, 8, 10, 11, and 12. Video was reviewed using 1-min instantaneous scans (as validated by Miller-Cushon and DeVries, 2011b) for $24 \mathrm{~h} / \mathrm{d}$. At each scanning interval, whether the calf was consuming feed (defined as taking place when a calf's head was lowered in the feed bucket) was recorded.

Lying behavior was recorded on the same weeks that feeding behavior was recorded, using electronic data loggers (Hobo Pendant G Data Logger, Onset, Pocasset, MA). These devices measured leg orientation at 1-min intervals and allowed all lying behavior data to be collected electronically (as validated by Bonk et al., 2013). The loggers were placed on the calves' rear leg with bandaging tape (Vetrap Bandaging Tape, 3M, London, ON, Canada), before $1000 \mathrm{~h}$ on d 1 of each recording week and removed after $7 \mathrm{~d}$ of complete recordings.

Fresh samples of the TMR and orts from all animals were taken for DM and nutrient composition analysis (Table 1) on d 1, 3, and 5 of each week. Duplicate 
Table 1. Ingredient and chemical composition and calculated nutrients of the fed $\operatorname{diets}^{1}$

\begin{tabular}{|c|c|c|c|}
\hline \multirow[b]{2}{*}{ Composition } & \multicolumn{3}{|c|}{ Diet } \\
\hline & $70 \%$ & $85 \%$ & TMR \\
\hline \multicolumn{4}{|c|}{ Ingredient $(\%$ of $\mathrm{DM})$} \\
\hline Concentrate $^{2}$ & 70 & 85 & - \\
\hline Wheat straw ${ }^{3}$ & 30 & 15 & - \\
\hline Corn silage ${ }^{4}$ & - & - & 42.3 \\
\hline Haylage $^{5}$ & - & - & 57.7 \\
\hline \multicolumn{4}{|c|}{$\begin{array}{l}\text { Chemical composition (\% of DM, } \\
\text { unless otherwise noted) }\end{array}$} \\
\hline $\mathrm{DM}(\%)$ & $90.9 \pm 0.41$ & $91.2 \pm 0.91$ & $52.7 \pm 0.83$ \\
\hline $\mathrm{CP}$ & $19.8 \pm 1.14$ & $23.1 \pm 0.85$ & $12.7 \pm 0.14$ \\
\hline $\mathrm{ADF}$ & $25.8 \pm 1.18$ & $20.4 \pm 0.70$ & $28.6 \pm 1.63$ \\
\hline NDF & $41.8 \pm 1.70$ & $35.1 \pm 0.88$ & $41.7 \pm 1.98$ \\
\hline $\mathrm{NFC}^{6}$ & $27.2 \pm 0.98$ & $29.4 \pm 1.76$ & $36.8 \pm 2.19$ \\
\hline \multicolumn{4}{|c|}{ Calculated nutrients ${ }^{7}$ (Mcal $/ \mathrm{kg}$ of DM) } \\
\hline $\mathrm{ME}$ & $2.4 \pm 0.03$ & $2.6 \pm 0.06$ & $2.3 \pm 0.03$ \\
\hline $\mathrm{NE}_{\mathrm{G}}$ & $0.9 \pm 0.03$ & $1.1 \pm 0.05$ & $0.8 \pm 0.03$ \\
\hline $\mathrm{NE}_{\mathrm{M}}$ & $1.5 \pm 0.03$ & $1.7 \pm 0.06$ & $1.4 \pm 0.03$ \\
\hline $\mathrm{TDN}^{8}$ & $65.1 \pm 0.91$ & $71.0 \pm 1.76$ & $63.5 \pm 0.85$ \\
\hline \multicolumn{4}{|c|}{ 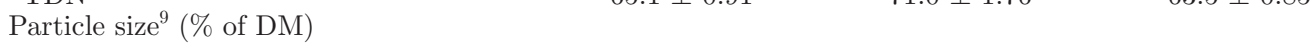 } \\
\hline Long & $3.5 \pm 1.76$ & $1.2 \pm 1.31$ & $19.8 \pm 3.98$ \\
\hline Medium & $67.8 \pm 6.10$ & $67.9 \pm 6.42$ & $38.1 \pm 1.83$ \\
\hline Short & $24.0 \pm 5.09$ & $27.2 \pm 5.13$ & $33.3 \pm 1.72$ \\
\hline Fine & $4.6 \pm 1.34$ & $3.7 \pm 1.77$ & $8.8 \pm 0.92$ \\
\hline
\end{tabular}

${ }^{1} 70 \%=$ diet with 70:30 concentrate-to-straw ratio; $85 \%=$ diet with 85:15 concentrate-to-straw ratio.

${ }^{2}$ ShurGain Optivia 22\% Rumimax Transition Calf Ration (Nutreco Canada, Guelph, Ontario, Canada), containing: corn gluten feed, soymeal, wheat shorts, corn distiller dried grains, canola meal, corn, calcium carbonate, salt, urea, Optivia dairy heifer micro, vitamin A, D, and E premix, magnesium oxide, selenium, Rumensin, beet pulp, citrus pulp, cottonseed hulls, micronized corn, and molasses. Concentrate had DM of $91.4 \pm 0.7 \%$ and chemical composition (DM basis) of $25.4 \pm 0.8 \% \mathrm{CP}, 12.5 \pm 0.7 \% \mathrm{ADF}, 27.7 \pm 1.0 \% \mathrm{NDF}$, and $32.2 \pm$ $1.4 \%$ NFC.

${ }^{3}$ Wheat straw had DM of $90.4 \pm 1.2 \%$ and chemical composition (DM basis) of $3.6 \pm 0.1 \% \mathrm{CP}, 56.0 \pm 0.8 \%$ $\mathrm{ADF}$, and $79.8 \pm 1.0 \%$ NDF. Particle size distribution of wheat straw (DM basis) was $13.8 \pm 7.8 \%$ long, 38.9 $\pm 6.1 \%$ medium, $34.2 \pm 3.7 \%$ short, and $13.1 \pm 3.0 \%$ fine particles.

${ }^{4}$ Corn silage had DM of $45.7 \pm 0.3 \%$ and chemical composition (DM basis) of $8.4 \% \mathrm{CP}, 17.1 \% \mathrm{ADF}$, and $30 \%$ NDF. Particle size distribution of corn silage (DM basis) was $11.4 \pm 2.7 \%$ long, $45.4 \pm 0.9 \%$ medium, $37.7 \pm$ $1.4 \%$ short, and $5.5 \pm 0.4 \%$ fine particles.

${ }^{5}$ Haylage was a mix of red clover (50\%), timothy grass (40\%), and orchard grass (10\%) based on seeding rate; it had DM of $62.4 \pm 2.9 \%$ and chemical composition (DM basis) of $14.8 \% \mathrm{CP}, 35.2 \% \mathrm{ADF}$, and $50.4 \%$ NDF. Particle size distribution of haylage (DM basis) was $43.7 \pm 3.6 \%$ long, $24.5 \pm 2.9 \%$ medium, $23.9 \pm 0.1 \%$ short, and $7.9 \pm 0.9 \%$ fine particles.

${ }^{6}$ Calculated according to NRC (2001) equations.

${ }^{7} \mathrm{NFC}=100-(\% \mathrm{NDF}+\% \mathrm{CP}+\%$ ether extract $+\%$ ash $)$.

${ }^{8}$ Calculated from ingredients.

${ }^{9}$ Particle size determined by Penn State Particle Separator (Nasco, Fort Atkinson, WI), which has a 19-mm screen (long), 8-mm screen (medium), 1.18-mm screen (short), and a pan (fine).

samples of the fresh TMR and orts were taken on those days for particle separation and sorting analysis. Component samples of the concentrate and straw were taken for DM and nutrient composition (Table 1) on d 3 of each week. A duplicate of the straw was taken at those times for particle separation. While feeding the silage-based TMR, fresh feed and orts samples were taken as previously described. Component samples of the haylage and corn silage were taken for DM and nutrient composition (Table 1) on d 3 of each week and pooled across wk 11to 12. A duplicate sample of both components was also taken at that time for particle separation. All samples were immediately frozen at $-20^{\circ} \mathrm{C}$ until they were further analyzed. The DM content of the samples taken for nutrient analysis was determined by drying the samples in an oven at $55^{\circ} \mathrm{C}$ for $48 \mathrm{~h}$. All DM samples were then ground to pass through a 1-mm screen (Wiley Mill, Arthur H. Thomas Co., Philadelphia, PA). Fresh TMR samples were pooled by week and orts samples were pooled by period and sent to Cumberland Valley Analytical Services Inc. (Maugansville, MD) for analysis of DM $\left(135^{\circ} \mathrm{C}\right.$; AOAC International, 2000; method 930.15$)$, ash $\left(535^{\circ} \mathrm{C}\right.$; AOAC International, 2000; method 942.05), ADF (AOAC International, 2000; method 973.18), NDF with heat-stable $\alpha$-amylase and sodium sulfite (Van Soest 
et al., 1991), fat (AOAC International, 2006; method 2003.05), and $\mathrm{CP}(\mathrm{N} \times 6.25$; AOAC International, 2000; method 990.03; Leco FP-528 Nitrogen Analyzer, Leco, St. Joseph, MI).

Sorting behavior was assessed through particle size separation of the fresh feed and orts using the 3 -screen $(19,8$, and $1.18 \mathrm{~mm})$ Penn State Particle Separator (Kononoff et al., 2003; Nasco, Fort Atkinson, WI). This device separated the particles into 4 fractions: long particles $(>19 \mathrm{~mm})$, medium particles $(<19$ to $>8 \mathrm{~mm})$, short particles $(<8$ to $>1.18 \mathrm{~mm}$ ), and fine particles $(<1.18 \mathrm{~mm})$. After separation, the DM of each separated fraction was determined by oven drying at $55^{\circ} \mathrm{C}$ for $48 \mathrm{~h}$.

Sorting activity for each fraction of the Penn State Particle Separator was calculated as the actual DMI of each fraction expressed as a percentage of the predicted DMI of that fraction (Leonardi and Armentano, 2003). The predicted intake of an individual fraction was calculated as the product of the DMI of the total diet multiplied by the DM percentage of that fraction in the fed TMR. Values equal to $100 \%$ indicated no sorting, $<100 \%$ indicated selective refusals (sorting against), and $>100 \%$ indicated preferential consumption (sorting for).

Meal analysis was performed on the feeding time data collected from video (as described previously) for individual calves. Meal criteria were determined using the approach described by DeVries et al. (2003): intervals between recorded periods of feeding were $\log _{10^{-}}$ transformed and their frequency distributions were approximated using 2 normal distributions (MIX 3.1.3; MacDonald and Green, 1988). The meal criterion was chosen as the time point at the intersection of the 2 distributions, with nonfeeding time intervals shorter in duration than the point of intersection occurring within meals and those longer in duration than the point of intersection occurring between meals. Meal criteria were determined for individual calves by dietary time period: wk 1 to 5 , wk 6 to 10 , and wk 11 to 12 . Meal criteria were similar between treatments $(P=0.43)$, but increased across periods $(P=0.02)$. Meal criteria averaged $15.8 \pm 1.00 \mathrm{~min}$ (mean $\pm \mathrm{SD}$ ) in wk 1 to 5 , $17.1 \pm 1.86 \mathrm{~min}$ in wk 6 to 10 , and $19.9 \pm 3.47 \mathrm{~min}$ in wk 11 to 12 . Meal criteria were used to calculate meal frequency (the number of intervals between visits to the feed pail that exceeded the meal criterion calculated for each calf) as well as meal duration (the sum of all recorded feeding time and all nonfeeding time periods shorter than the meal criterion). Additionally, meal duration was assessed separately for the first meal after feed delivery and all other meals of the day.

Data were analyzed separately by dietary time period: wk 1 to 5 when all calves were fed the same 85:15 concentrate-to-straw diet, wk 6 to 10 when calves were on different diets (85:15 and 70:30), and wk 11 to 12 when all calves were on the same silage-based TMR. For each time period, feed intake, growth, sorting, and behavior data, including daily meal data, were averaged for each calf by week. Prior to analyses, all data were screened for normality using the UNIVARIATE procedure of SAS (SAS Institute, 2013). Sorting activity for each particle fraction was tested within treatment for a difference from $100 \%$ using the TTEST procedure of SAS (SAS Institute, 2013). To examine the effect of treatment, all data were analyzed using the MIXED procedure of SAS (SAS Institute, 2013), treating week as a repeated measure. The model included the fixed effects of week, treatment, week $\times$ treatment interaction, and the random effect of calf. Compound symmetry was selected as the variance-covariance matrix structure on the basis of best fit according to Schwarz's Bayesian information criterion.

For analyses of diurnal patterns of feeding time, data were summarized by calculating the mean hourly total of feeding time for each calf and hour in each week. Data were analyzed using the MIXED procedure of SAS (SAS Institute, 2013), treating hour and week as repeated measures. The model included the fixed effects of treatment, hour, and week, all 2-way interactions, and the 3-way interaction. Calf was considered a random effect and hour and week were considered repeated measures. Unstructured by compound symmetry was selected as the variance-covariance matrix structure on the basis of best fit according to Schwarz's Bayesian information criterion. For all models, significance was declared at $P \leq 0.05$, and trends reported if $0.05<P \leq 0.10$.

As all calves were offered the same diet during wk 1 to 5 of the study, no differences were observed between treatments and data are presented here for reference: DMI $(5.5 \pm 0.33 \mathrm{~kg} / \mathrm{d}$; mean $\pm \mathrm{SE}), \mathrm{BW}(165.8 \pm 7.35$ $\mathrm{kg})$, ADG $(1.7 \pm 0.09 \mathrm{~kg} / \mathrm{d})$, feed-to-gain ratio $(3.5 \pm$ $0.15 \mathrm{~kg}$ of $\mathrm{DM} / \mathrm{kg}$ of gain), feeding time $(151.9 \pm 8.77$ $\mathrm{min} / \mathrm{d})$, lying time $(1008.5 \pm 17.20 \mathrm{~min} / \mathrm{d})$, and sorting of various particle fractions (long $=77.5 \pm 3.24 \%$; medium $=102.6 \pm 0.22 \%$; short $=99.2 \pm 0.32 \%$; and fine $=74.2 \pm 1.78 \%$ ).

Once calves were offered diets differing in forage inclusion rate in wk 6 to 10, DMI was lower for calves fed the $70 \%$ diet compared with the $85 \%$ diet (Table 2 ). Higher inclusion rate of straw on the $70 \%$ diet increased the NDF content of the diet considerably (Table 1). Although this may have contributed to decreased DMI for calves on the $70 \%$ diet (Quigley et al., 1986; Mertens, 1997), calves on the $85 \%$ diet tended to consume more total $\mathrm{NDF}$ as a percent of $\mathrm{BW}(1.12$ vs. 1.03 ; $\mathrm{SE}=$ 0.038; $P=0.08)$, suggesting that voluntary feed intake 
in those calves fed the $70 \%$ diet was limited more by physical rumen fill (Quigley et al., 1986). Because of the differences in intake and nutrient densities of the diet, $\mathrm{ADG}$ was less $(\mathrm{SE}=0.08 ; P=0.015)$ for the $70 \%$ treatment $(1.25 \mathrm{~kg} / \mathrm{d})$ compared with the $85 \%$ treatment $(1.59 \mathrm{~kg} / \mathrm{d})$ group in wk 6 to 10 . It is important to note that despite the higher NDF content of the $70 \%$ diet, the efficiency of feed conversion was similar between the 70 and $85 \%$ diets (4.90 vs. $5.10 \mathrm{~kg}$ of $\mathrm{DM} / \mathrm{kg}$ of gain; $\mathrm{SE}=0.3 ; P=0.6$ ). This may have been partially related to differences in feed sorting. As hypothesized, calves on the $70 \%$ diet sorted their diet more, sorting against long particles (62.8 vs. $103.8 \%$; $\mathrm{SE}=6.3 ; P=0.01)$ and for medium particles $(105.0$ vs. $101.3 \%$; $\mathrm{SE}=0.5 ; P=0.001)$ more than on the $85 \%$ diet. As result, NDF intake on the $70 \%$ diet was $7 \%$ lower (at $2.15 \mathrm{~kg} / \mathrm{d}$ ) than predicted based on dietary formulation, whereas it was only $2 \%$ lower (at 2.53 $\mathrm{kg} / \mathrm{d}$ ) on the $85 \%$ diet. Thus, it is possible that the diet consumed by calves on the $70 \%$ diet would have been more digestible than predicted, potentially improving feed efficiency.

No overall differences in intake were noted between treatment groups once calves were offered the common silage-based TMR in wk 11 to 12 (Table 2). A week $x$ treatment interaction reflected an increase in DMI from wh 11 to 12 for calves previously fed the $85 \%$ diet, whereas DMI decreased from wk 11 to 12 for calves previously fed the $70 \%$ diet. Average daily gain (1.07 vs. $1.16 \mathrm{~kg} / \mathrm{d} ; \mathrm{SE}=0.15 ; P=0.7)$ and efficiency ( 5.71 vs. $5.18 \mathrm{~kg}$ of $\mathrm{DM} / \mathrm{kg}$ of gain; $\mathrm{SE}=0.75 ; P=0.6$ ) were also similar in wk 11 to 12 . This suggests that their prior feeding program had no effect on the ability of calves to transition to consume and digest a silagebased diet.

In the current study, during wk 6 to 10, feeding time peaked following feed delivery (Figure 1a), which is characteristic for dairy cattle, both young and mature (DeVries and von Keyserlingk, 2005, 2009; Greter et al., 2010a; Miller-Cushon et al., 2013a). Inclusion of more straw in the diet $(70 \%$ diet) slowed the rate of consumption and increased the amount of time calves spend eating (Table 2). A treatment $\times$ hour interaction $(P<0.001)$ in the analysis of diurnal feeding patterns (Figure 1a) indicated that calves offered the $70 \%$ diet spent more time feeding in the first $8 \mathrm{~h}$ after feed delivery, explaining their greater daily feeding times. This is also reflected in the $3 \times$ duration of the first meal after feed delivery for calves offered the $70 \%$ diet (Table 2 )

This increased feeding activity likely contributed to those calves also spending less time lying down (Table 2 ). As previously mentioned, when fed the $70 \%$ diet,

Table 2. Behavior measures from calves in wk 6 to 10 and 11 to 12 for the different treatments

\begin{tabular}{|c|c|c|c|c|c|c|}
\hline \multirow[b]{2}{*}{ Item } & \multicolumn{2}{|c|}{ Treatment $(\mathrm{T})^{1}$} & \multirow[b]{2}{*}{$\mathrm{SE}$} & \multicolumn{3}{|c|}{$P$-value } \\
\hline & $70 \%$ & $85 \%$ & & $\mathrm{~W}^{2}$ & $\mathrm{~T}$ & $\mathrm{~W} \times \mathrm{T}$ \\
\hline \multicolumn{7}{|l|}{ Weeks 6 to $10^{3}$} \\
\hline DMI (kg/d) & 5.53 & 7.38 & 0.339 & $<0.001$ & 0.005 & 0.33 \\
\hline Feeding time $(\min / \mathrm{d})$ & 194.9 & 102.6 & 12.45 & 0.18 & 0.001 & 0.005 \\
\hline Rate of intake ( $\mathrm{g}$ of $\mathrm{DM} / \mathrm{min}$ ) & 30.2 & 74.3 & 5.05 & 0.037 & $<0.001$ & 0.05 \\
\hline Meal frequency (no./d) & 10.7 & 11.9 & 0.80 & 0.008 & 0.33 & 0.67 \\
\hline Meal duration (min/meal) & 31.6 & 18.4 & 3.23 & 0.21 & 0.003 & 0.55 \\
\hline Duration of first meal & 91.3 & 28.3 & 9.07 & 0.028 & 0.042 & 0.001 \\
\hline Duration of other meals & 25.1 & 17.3 & 1.81 & 0.73 & 0.015 & 0.47 \\
\hline Lying time $(\min / \mathrm{d})$ & 967.1 & 1021.1 & 13.93 & 0.12 & 0.026 & 0.29 \\
\hline Lying bouts (no./d) & 13.3 & 16.1 & 0.66 & 0.033 & 0.016 & 0.56 \\
\hline \multicolumn{7}{|l|}{ Weeks 11 to $12^{4}$} \\
\hline DMI $(\mathrm{kg} / \mathrm{d})$ & 5.19 & 5.15 & 0.279 & 0.83 & 0.90 & 0.001 \\
\hline Feeding time $(\min / \mathrm{d})$ & 164.3 & 136.8 & 12.03 & 0.001 & 0.15 & 0.046 \\
\hline Rate of intake (g of DM/min) & 33.7 & 39.7 & 4.29 & 0.002 & 0.35 & 0.82 \\
\hline Meal frequency (no./d) & 9.0 & 10.2 & 0.46 & 0.022 & 0.10 & 0.009 \\
\hline Meal duration (min/meal) & 42.1 & 32.6 & 2.91 & 0.36 & 0.051 & 0.021 \\
\hline Duration of first meal & 49.4 & 32.3 & 3.40 & 0.21 & 0.007 & 0.023 \\
\hline Duration of other meals & 37.5 & 32.1 & 2.67 & 0.50 & 0.19 & 0.10 \\
\hline Lying time $(\min / \mathrm{d})$ & 958.5 & 984.5 & 16.45 & 0.004 & 0.3 & 0.61 \\
\hline Lying bouts (no./d) & 11.4 & 11.1 & 0.51 & 0.44 & 0.75 & 0.13 \\
\hline
\end{tabular}




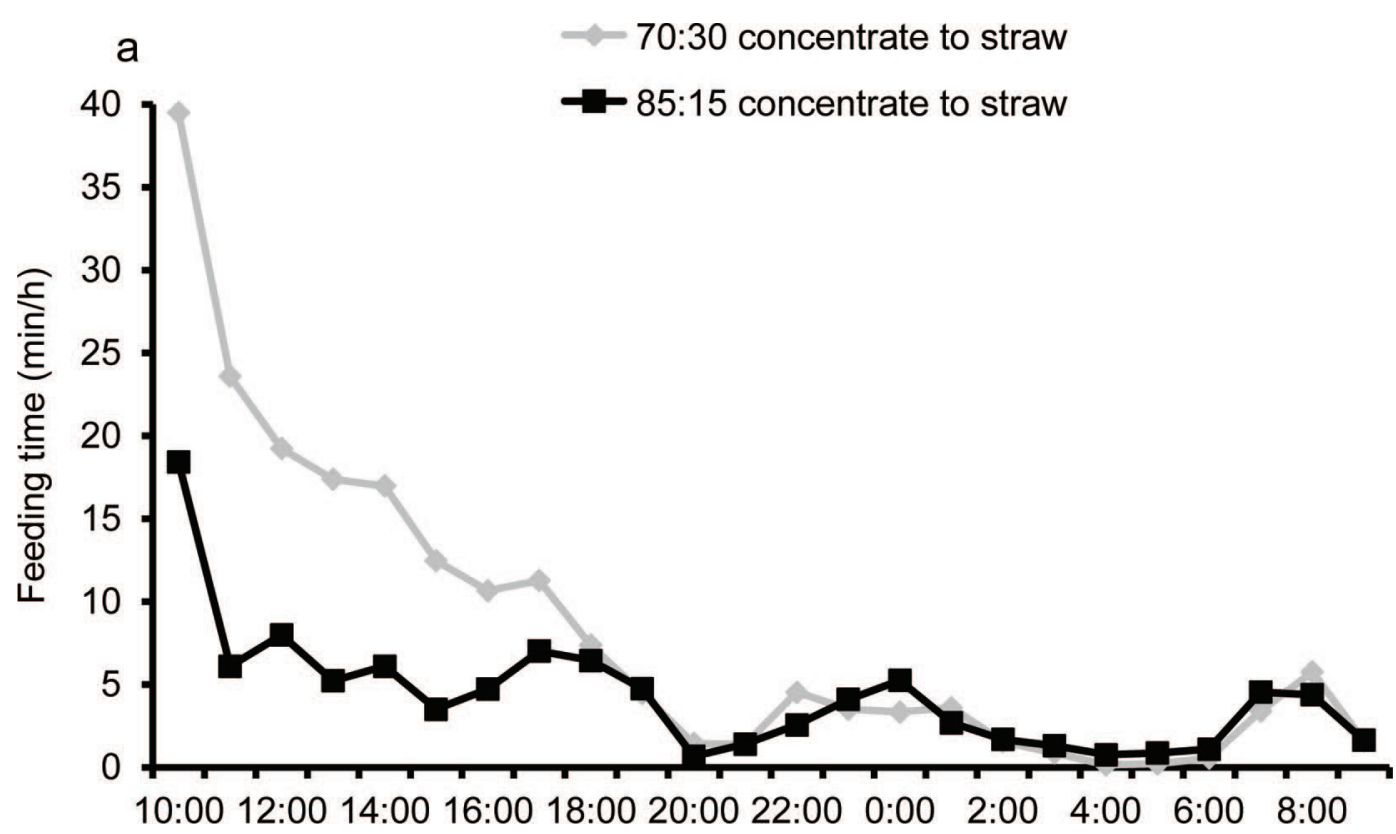

b

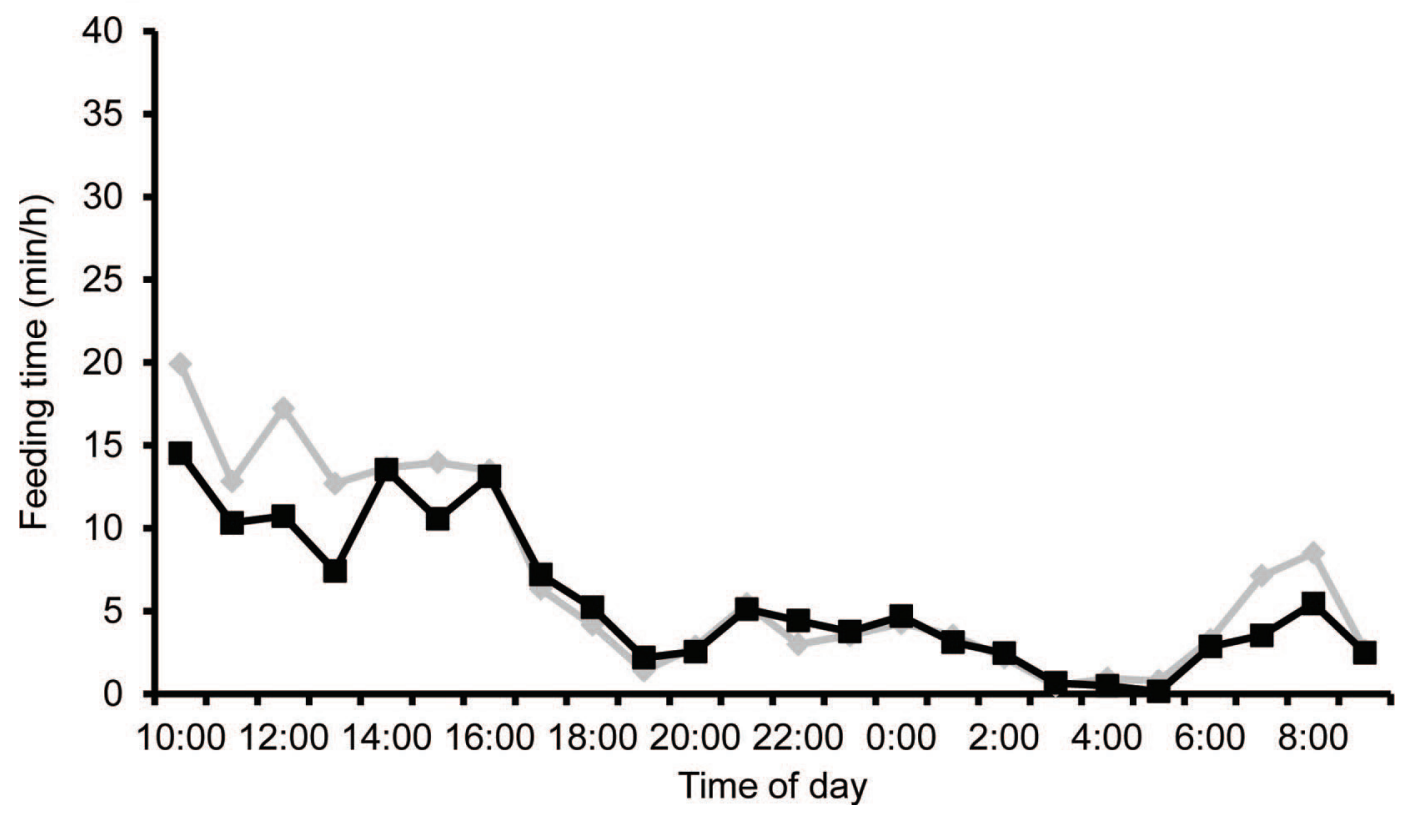

Figure 1. Diurnal feeding patterns of calves fed (DM basis) a 70:30 or 85:15 concentrate-to-straw diet in wk 6 to 10 ( $\mathrm{n}=5$ per treatment), whereas all calves were (a) on their respective treatment diets in wk 6 to $10(\mathrm{SE}=0.96)$ and (b) on a common 42:58 corn silage-to-haylage mixed ration in wk 11 to $12(\mathrm{SE}=1.26)$. Calves were delivered feed daily at $1000 \mathrm{~h}$. Feeding time is summarized by hour, with data averaged across $3 \mathrm{~d}$ of observation/wk for (a) wk 6, 8, and 10 and (b) for wk 11 and 12.

calves sorted against the long straw particles. This is consistent with the results of Greter et al. (2008), who reported that growing heifers (35 wk old) sorted their TMR significantly more when greater amounts of straw were added to their diet. In addition, these researchers also observed lower DMI and increased feeding time when heifers were provided with increased amounts of straw in their diet, which resulted in a decreased rate of feed intake, similar to the current study. Given the greater extent of sorting in wk 6 to 10 by calves on the $70 \%$ diet in the present study, it could be suggested that those calves were spending more time engaged in 
selectively consuming their diet (against the longest particles) during that initial longer meal following feed delivery.

In the analysis of diurnal feeding activity in wk 11 to 12 (Figure $1 \mathrm{~b}$ ), a treatment $\times$ hour interaction was detected $(P=0.032)$; calves previously fed the $70 \%$ diet continued to spend more time feeding in the first few hours after feed delivery. Thus, as hypothesized, the diurnal feeding patterns seem to carry over after the dietary change from wk 6 to 10 to wk 11 to 12 . No interaction of treatment $\times$ hour $\times$ week $(P=0.3)$ indicated that this diurnal pattern remained consistent within treatment across these weeks. Consistent with differences in diurnal feeding patterns, the first meal of the day was $1.5 \times$ longer in duration for calves previously fed the $70 \%$ diet (Table 2). This carryover of feeding behavior is similar to the results of Greter et al. (2010b), who found that heifers consuming a TMR, but previously fed a top-dressed diet, spend more time at the feed bunk after feed delivery than heifers previously fed TMR. These current findings provide further evidence that early life feeding practices may affect the development and conditioning of behavioral patterns in dairy cattle (DeVries, 2010).

There was a week $\times$ treatment interaction for feeding time during wk 11 to $12(P=0.046)$; reflecting the changes in DMI over this time period, this interaction revealed a decrease in feeding time from wk 11 to 12 for calves previously fed the $70 \%$ diet, whereas it did not change for calves previously fed the $85 \%$ diet. This suggests that any carryover effect on daily feeding time diminished by the second week on the novel TMR, reflecting the decrease in DMI from wk 11 to 12 for calves previously-fed the $70 \%$ diet, whereas the diurnal distribution of feeding time remained consistent (Figure 1b). As described by Greter et al. (2010b), this type of feeding pattern, in particular engaging in a long meal following feed delivery, could be undesirable if carried into adulthood, where it can have negative effects on rumen fermentation patterns. It would, therefore, be interesting to determine in future work if that difference in patterning of feeding, which remained consistent over $2 \mathrm{wk}$, diminished over a longer time period or persisted.

Despite the effect on feeding patterns, there was no carryover effect on feed sorting in wk 11 to 12 . In fact, no difference in sorting was observed between treatments during wk 11 to 12 , with all calves sorting for long particles $(105.3 \%)$, not sorting for or against medium (99.0\%) and small (98.8\%) particles, and sorting against fine particles (97.0\%). Similarly, Greter et al. (2010b) reported no persistent differences in pattern of feed sorting resulting from previous experience in weaned heifers. This suggests that, in calves with previous experience sorting feed, the pattern of feed sorting may depend more on physical and chemical characteristics of the presented ration than previously expressed patterns of sorting.

In summary, we found that diluting a dry TMR, containing a multitextured concentrate and chopped straw, with more straw resulted in calves spending more time feeding and having longer meals immediately after feed delivery; this feeding pattern carried over after calves were transitioned to a silage-based ration. This suggests that, in an applied setting, nutritional strategies that promote consumption of feed in longer meals immediately after feed delivery should be avoided for dairy calves early in life, as these feeding patterns, if reinforced, may persist and have negative effects later in life.

\section{ACKNOWLEDGMENTS}

We thank the staff and students at the University of Guelph, Kemptville Campus Dairy Education and Research Centre. In particular, we thank Megan Bruce and Morgan Overvest of the University of Guelph, Kemptville Campus, for their technical assistance and Emily Miller-Cushon (University of Florida, Gainesville) for her assistance with the meal analysis and comments on the manuscript. This project was funded through a Natural Sciences and Engineering Research Council of Canada (NSERC, Ottawa, ON, Canada) Engage Grant (T. J. DeVries) with support from Nutreco Canada Inc. (Guelph, ON, Canada). This project was also supported through contributions from the Canadian Foundation for Innovation (CFI; Ottawa, ON, Canada) and the Ontario Research Fund (Toronto, ON, Canada).

\section{REFERENCES}

AOAC International. 2000. Official Methods of Analysis. Vol. I. 17th ed. AOAC International, Arlington, VA.

AOAC International. 2006. Official Methods of Analysis. Vol. I. 18th ed. AOAC International. Arlington, VA.

Bonk, S., O. Burfeind, V. S. Suthar, and W. Heuwieser. 2013. Evaluation of data loggers for measuring lying behavior in dairy calves. J. Dairy Sci. 96:3265-3271.

CCAC (Canadian Council on Animal Care). 2009. CCAC Guidelines on the Care and Use of Farm Animals in Research, Teaching and Testing. CCAC, Ottawa, ON, Canada.

Coppock, C. E., D. L. Bath, and B. Harris Jr.. 1981. From feeding to feeding systems. J. Dairy Sci. 64:1230-1249.

DeVries, T. J. 2010. Review: Behavior and its role in the nutritional management of the growing dairy heifer. Can. J. Anim. Sci. 90:295-302.

DeVries, T. J., and M. A. G. von Keyserlingk. 2005. Time of feed delivery affects the feeding and lying patterns of dairy cows. J. Dairy Sci. 88:625-631.

DeVries, T. J., and M. A. G. von Keyserlingk. 2009. Feeding method affects the feeding behavior of growing dairy heifers. J. Dairy Sci. 92:1161-1168

DeVries, T. J., M. A. G. von Keyserslingk, D. M. Weary, and K. A. Beauchemin. 2003. Measuring the feeding behaviour of lactating dairy cows in early to peak lactation. J. Dairy Sci. 86:3354-3361. 
Greter, A. M., T. J. DeVries, and M. A. G. von Keyserlingk. 2008. Nutrient intake and feeding behavior of growing heifers: effects of dietary dilution. J. Dairy Sci. 91:2786-2795.

Greter, A. M., K. E. Leslie, G. J. Mason, B. W. McBride, and T. J. DeVries. 2010a. Effect of feed delivery method on the behavior and growth of dairy heifers. J. Dairy Sci. 93:1668-1676.

Greter, A. M., K. E. Leslie, G. J. Mason, B. W. McBride, and T. J. DeVries. 2010b. Feed delivery method affects the learning of feeding and competitive behavior in dairy heifers. J. Dairy Sci. 93:3730-3737.

Hintze, J. 2008. PASS 2008. NCSS LLC, Kaysville, UT.

Kononoff, P. J., A. J. Heinrichs, and D. R. Buckmaster. 2003. Modification of the Penn State Particle Separator and the effects of moisture content on its measurements. J. Dairy Sci. 86:1858-1863.

Leonardi, C., and L. E. Armentano. 2003. Effect of quantity, quality, and length of alfalfa hay on selective consumption by dairy cows. J. Dairy Sci. 86:557-564.

MacDonald, P. D. M., and P. E. J. Green. 1988. User's Guide to Program MIX: An Interactive Program for Fitting Mixtures of Distributions. Release 2.3, January 1988. Ichthus Data Systems, Hamilton, ON, Canada.

Mertens, D. R. 1997. Creating a system for meeting the fiber requirements of dairy cows. J. Dairy Sci. 80:1463-1481.
Miller-Cushon, E. K., R. Bergeron, K. E. Leslie, G. J. Mason, and T J. DeVries. 2013a. Effect of feed presentation on feeding patterns of dairy calves. J. Dairy Sci. 96:7260-7268.

Miller-Cushon, E. K., R. Bergeron, K. E. Leslie, G. J. Mason, and T. J. DeVries. 2013b. Effect of early exposure to different feed presentations on feed sorting of dairy calves. J. Dairy Sci. 96:4624-4633.

Miller-Cushon, E. K., and T. J. DeVries. 2011a. Effect of early feed type exposure on diet selection behavior of dairy calves. J. Dairy Sci. $94: 342-350$.

Miller-Cushon, E. K., and T. J. DeVries. 2011b. Validation of methodology for characterization of feeding behavior in dairy calves. J. Dairy Sci. 94:6103-6110.

Morris, T. R. 1999. Experimental Design and Analysis in Animal Sciences. CABI Publishing, New York, NY.

NRC. 2001. Nutrient Requirements for Dairy Cattle. Natl. Acad. Sci. Washington, DC

Quigley, J. D., III, R. E. James, and M. L. McGilliard. 1986. Dry matter intake in dairy heifers. 1. Factors affecting intake of heifers under intensive management. J. Dairy Sci. 69:2855-2862.

SAS Institute. 2013. SAS version 9.4. SAS Institute Inc., Cary, NC.

Van Soest, P. J., J. B. Robertson, and B. A. Lewis. 1991. Methods for dietary fiber, neutral detergent fiber and non-starch polysaccharide in relation to animal nutrition. J. Dairy Sci. 74:3583-3597. 